\title{
Phenalen-1-one-mediated photodynamic therapy inhibits keloid graft progression by reducing vessel formation and promoting fibroblast apoptosis
}

\author{
Wei Zheng ${ }^{\mathrm{A}, \mathrm{D}, \mathrm{E}}$, Haiyan $\mathrm{Wu}^{\mathrm{A}, \mathrm{B}, \mathrm{D}}$, Ying $\mathrm{Li}^{\mathrm{A}, \mathrm{B}, \mathrm{E}}$, Helin Li $\mathrm{L}^{\mathrm{B}, \mathrm{E}}$, \\ Zhaojun Liu ${ }^{B, E}$, Yongzhi Nie ${ }^{C, E}$, Lingling Shi ${ }^{C}, E$, Hongyu Wang ${ }^{A, E, F}$ \\ Department of Burn Orthopedics, Xingtai People's Hospital, China \\ A - research concept and design; $B$ - collection and/or assembly of data; $C$ - data analysis and interpretation; \\ $\mathrm{D}$ - writing the article; $\mathrm{E}$ - critical revision of the article; $\mathrm{F}$ - final approval of the article
}

Address for correspondence

Hongyu Wang

E-mail:uyv12254@126.com

Funding sources

None declared

Conflict of interest

None declared

Received on August 20, 2020

Reviewed on September 12, 2020

Accepted on November 18, 2020

Published online on April 29, 2021

Cite as

Zheng W, Wu H, Li Y. Phenalen-1-one-mediated photodynamic therapy inhibits keloid graft progression by reducing vessel formation and promoting fibroblast apoptosis. Adv Clin Exp Med. 2021;30(4):431-439. doi:10.17219/acem/130594

DOI

10.17219/acem/130594

Copyright

Copyright by Author(s)

This is an article distributed under the terms of the

Creative Commons Attribution 3.0 Unported (CC BY 3.0)

(https://creativecommons.org/licenses/by/3.0/)

\section{Abstract}

Background. Keloid is a unique refractory syndrome characterized by a proliferation disorder of the fibroblasts. Recently, photodynamic therapy (PDT) has become a promising technique to modulate fibroblasts. However, use of the photosensitizer Phenalen-1-one (Ph1) in PDT for keloid remains to be explored.

Objectives. This study investigated the efficacy of Ph1-PDT in the in vitro and in vivo models of keloid.

Materials and methods. Cell viability was assessed with a Cell Counting Kit-8 (CCK-8) analysis in keloid fibroblasts. The migrated and invaded keloid fibroblasts after Ph1-PDT were detected using scratch and matrigel invasion assays in vitro. Flow cytometry measured the apoptosis changes. The protein concentrations and the mRNA expression of inflammatory modulators (interleukin 8 (IL-8) and IL-1B) were determined using enzyme-linked immunosorbent assay (ELISA) and real-time quantitative polymerase chain reaction (RT-qPCR) methods, respectively. Nude mice were used to perform the transplantation of keloid grafts. Western blot analysis measured the protein expression of CD31, CD34, tumor growth factor $\beta 1$ (TGF- $\beta 1$ ), and collagen 1 in keloid fibroblasts and grafts.

Results. Our results revealed that Ph1-PDT significantly suppressed cell viability, migration and invasion, and enhanced the rate of cell apoptosis and caspase-3 expression in keloid fibroblasts. Moreover, in the nude mice model, Ph1-PDT decreased the volume of the graft and attenuated the vessel density by inhibiting the expression of vessel density biomarkers (CD31 and CD34) in keloid grafts. Furthermore, Ph1-PDT signifcantly inactivated the inflammatory mediators in keloid grafts. In addition, Ph1-PDT considerably attenuated the development of keloids by inhibiting TGF- $\beta 1$ and collagen 1 proteins in keloid fibroblasts and grafts.

Conclusions. Ph1-PDT may suppress keloid progression by reducing vessel formation and inflammation, and promoting fibroblast apoptosis, suggesting a potential therapy method for keloid.

Key words: TGF- $\beta 1$, photodynamic therapy, phenalen-1-one, keloid graft, collagen 1 


\section{Background}

Keloid is a skin disorder that results in pathological scars. This condition is characterized by inflammation, abnormal deposition of collagen fibers, and excessive proliferation of fibroblasts with cancer-like properties that are usually invasive and often recur after excision. ${ }^{1}$ The abnormal growth of keloid can be disfiguring, and cause pain and irritation. ${ }^{2}$ Keloid also generally leads to psychological and physical anxiety in patients. ${ }^{3}$ There are various treatments for keloids, such as radiation therapy, corticosteroid injections, surgical excision, pressure therapy, and silicone gel sheeting. ${ }^{4}$ However, few of the current therapeutic modalities provide good clinical outcomes without side effects. Surgical excision is an efficient method compared to others, yet it might add to a higher risk of cancer years after the radiation exposure. ${ }^{5}$ Therefore, it is urgent to explore an effective and safe therapy for keloid scarring.

Photodynamic therapy (PDT) is a promising therapeutic strategy used to treat skin lesions, including actinic keratosis, Bowen's disease and basal cell carcinoma. ${ }^{6}$ The PDT has been widely used to treat keloid due to its accuracy and minimal side effects. ${ }^{7}$ This method kills bacteria through an oxidative burst, leading to damage in biomolecules and cell structures. ${ }^{8}$ It consists of 3 main components: molecular oxygen, light of a proper wavelength and a non-toxic dye (photosensitizer (PS)). ${ }^{9}$ Briefly, the PS is absorbed into the target cells and exposed to the radiation of visible light with a wavelength of $400-750 \mathrm{~nm}$. The abovementioned components of PDT cannot induce cytotoxic effects alone. However, when they are joined together, reactive oxygen (RO) occurs, inducing cellular apoptosis. ${ }^{10}$ The accurate supply of light to the target cells enables PDT to eliminate a large number of cancer cells with minimal adverse effects. ${ }^{11}$ An appropriate amount of light is required to activate the PS, as it is considered a light-absorbing molecule. The oxidation reactions of the radicals are promoted due to the excited PS, which leads to the generation of numerous RO derivatives, including peroxyl radical (ROO•), superoxide radical anion $\left(\mathrm{O}_{2} \bullet^{-}\right)$and hydroxyl radical (HO•). ${ }^{12}$ The PS also transfers its energy to the molecular oxygen to generate singlet oxygen $\left({ }^{1} \mathrm{O}_{2}\right) \cdot{ }^{13}$ Previous research has revealed that HMME-PDT activates the apoptosis of keloid fibroblasts in vitro. ${ }^{14}$ Also, PDT directly triggers apoptosis in targeted cells due to the formation of reactive oxygen species (ROS) in the proximity of, or in, the mitochondria of the cells. ${ }^{15}$

Optimal performance of PDT depends on the type of PS used and, recently, several PSs have been applied in clinical treatment. However, these PSs have certain limitations, including excessive potency and inadequate discernment of the site of the lesion. Therefore, a new PS that can improve the efficacy of PDT is urgently needed. ${ }^{16}$ Phenalen1-one (Ph1) is a newly developed PS that is extracted from Scutellaria barbata, an ethnopharmacological herb. ${ }^{17} \mathrm{Ph} 1$ exhibits ROS-mediated properties against plant-parasitic nematodes and vector mosquito larvae, which are increased in the presence of light. ${ }^{18}$ In addition, $\mathrm{Ph} 1$ induces the photo-inactivation of key oral bacteria and acts as a potential dental drug. ${ }^{19}$ However, the role and mechanism of Ph1-PDT in the treatment of keloids remain unknown.

\section{Objectives}

The current study aimed to explore the impacts of Ph1PDT on the viability, invasion, migration, and apoptosis of keloid fibroblasts in vitro. Also, the effects of Ph1-PDT on keloid graft growth and vessel density were determined in vivo. Moreover, the efficiency and mechanism of Ph1PDT for vascular remodeling was evaluated in a mouse model. Triamcinolone acetonide (TA) was used as a positive control in these latter experiments as it is widely recognized that this agent significantly suppresses keloid in vivo. ${ }^{20}$ Furthermore, the impact of Ph1-PDT on inflammatory cytokines was examined in keloid grafts. The current findings may provide an efficient therapeutic strategy for the treatment of keloids.

\section{Materials and methods}

\section{Keloid fibroblast culture}

Human keloid fibroblasts were obtained from American Type Culture Collection (ATCC, Manassas, USA) and cultured in Dulbecco's modified Eagle's medium (DMEM; Thermo Fisher Scientific, Waltham, USA) with penicillin $\left(100 \mathrm{U} \mathrm{mL}^{-1}\right)$, streptomycin $\left(100 \mu \mathrm{g} \mathrm{mL}^{-1}\right)$ and $10 \%$ fetal bovine serum (FBS). The cells were incubated in humidified air conditions of $21 \% \mathrm{O}_{2}$ and $5 \% \mathrm{CO}_{2}$ at $37^{\circ} \mathrm{C}$. The cells from 3 through 6 passages were used in the experiments.

\section{Ph1-PDT in cells}

The cells were collected and inoculated into the culture plates, followed by the addition of various dosages $(1 \mu \mathrm{M}$, $3 \mu \mathrm{M}, 10 \mu \mathrm{M}$, and $30 \mu \mathrm{M})$ of Ph1 into the medium. These cells were then cultured for $4 \mathrm{~h}$ in the dark. Green light with a wavelength of $532 \mathrm{~nm}$ was then applied upright on the culture plates for another $12 \mathrm{~h}$. Non-light cell groups on the culture plate were covered with tinfoil, and the gaps in the culture plate were minimized by using sterilized gauze. After light treatment, the medium was instantly aspirated and rinsed with phosphate-buffered saline (PBS), followed by the addition of DMEM medium with $10 \%$ FBS.

\section{CCK-8 assay}

A Cell Counting Kit-8 (CCK-8; Beyotime, Shanghai, China) was used to measure the cell viability according to the manufacturer's protocols. More specifically, keloid 
fibroblasts were seeded in 96 -well plates $\left(5 \times 10^{3}\right.$ cells/ well), followed by treatment with different concentrations $(1 \mu \mathrm{M}, 3 \mu \mathrm{M}, 10 \mu \mathrm{M}$, and $30 \mu \mathrm{M})$ of $\mathrm{Ph} 1$, and exposure to a $100 \mathrm{~mW} \mathrm{~cm}^{-2}$ laser at a wavelength of $532 \mathrm{~nm}$ for $10 \mathrm{~min}$. Cells were also selected for triamcinolone acetonide (TA) $(1 \mathrm{mg} / \mathrm{mL})$ or DMEM treatment. The TA group served as a positive control while the DMEM group served as a negative control. The CCK-8 solution (10 $\mu \mathrm{L}$; SigmaAldrich, St. Louis, USA), 10\% FBS and $100 \mu \mathrm{L}$ of DMEM were added into each plate followed by incubation for $4 \mathrm{~h}$ at $37^{\circ} \mathrm{C}$ in a humidified incubator. A microplate reader (Bio-Rad, Hercules, USA) was used to read the optical density (OD) values at $450 \mathrm{~nm}$ at $0 \mathrm{~h}, 24 \mathrm{~h}, 48 \mathrm{~h}$, and $72 \mathrm{~h}$. All the measurements were repeated 3 times for each sample.

\section{Scratch migration assay}

Six-well plates were used to seed keloid fibroblasts and, after various treatments, the fibroblasts were scratched with pipette tips $(100 \mu \mathrm{L})$ and then washed twice using PBS. The scratched cells were incubated in a humidified incubator with $5 \% \mathrm{CO}_{2}$ at $37^{\circ} \mathrm{C}$. Wound closures were examined after different time intervals ( $0 \mathrm{~h}, 24 \mathrm{~h}$ and $48 \mathrm{~h}$ ) and the wound healing rates of the cells were calculated.

\section{Matrigel invasion assay}

The 24-well transwell chambers containing $8 \mathrm{~mm}$ pores (Bioz, Inc., Los Altos, USA) were used to conduct the cell invasion assay. Matrigel $(30 \mathrm{~mL})$ was used to coat the inserts. The upper matrigel chamber, supplemented with serum-free medium $(100 \mathrm{~mL})$, was used to seed fibroblasts $\left(5 \times 10^{3}\right)$ after different treatments, followed by incubation for $24 \mathrm{~h}$. Further, $10 \%$ FBS with $500 \mu \mathrm{L}$ of DMEM was added into the lower chamber. Crystal violet $(0.1 \%)$ was added to stain the cells, invaded cells were imaged, and the cell number was analyzed across 5 fields $(\times 100$ magnification) under a light microscope.

\section{Flow cytometry}

Six-well plates were used to inoculate the keloid fibroblasts of the logarithmic growth phase. After 1 day, a suspension of the culture was prepared with a cell density of $1 \times 10^{6}$ cells per milliliter. The cells were centrifuged (1000 rpm, $5 \mathrm{~min}, 4^{\circ} \mathrm{C}$ ), supernatants were resuspended in buffer solution and $5 \mu \mathrm{L}$ of Annexin V-FITC (Beyotime) was added. The culture was mixed gradually and incubated for $10 \mathrm{~min}$ in the dark. After centrifugation $(1000 \mathrm{rpm}$, $5 \mathrm{~min}, 4^{\circ} \mathrm{C}$ ), the supernatants were discarded and cells were suspended in $10 \mu \mathrm{L}$ of propidium iodide and $190 \mu \mathrm{L}$ of Annexin V-FITC for $15 \mathrm{~min}$ at room temperature. Flow cytometry (Biocompare, San Francisco, USA) was used to perform the quantitative analysis of apoptosis. All measurements were performed 3 times.

\section{ELISA assay}

Enzyme-linked immunosorbent assay (ELISA) was used to determine the concentrations of interleukin $1 \beta$ (IL-1 $\beta$; Human IL-1-beta ELISA Kit; Abcam, Cambridge, USA) and IL-8 (Human IL-8 ELISA Kit; Abcam) according to the manufacturer's protocol. The supernatants attained from the cell cultures were collected, and a microplate reader (BMG LabTech, Ortenberg, Germany) was used to detect absorbance at $450 \mathrm{~nm}$. The concentration of cytokines was calculated based on a standard curve derived from the data of standard samples. All the measurements were repeated in triplicate.

\section{RT-qPCR}

RiboZol RNA extraction reagent (VWR, Toronto, Canada) was used to extract total RNA from keloid tissues, and the concentration of RNA was measured using a NanoDrop 2000 spectrophotometer (Thermo Fisher Scientific). The cDNA was reverse transcribed using a PrimeScript RT Master Mix Kit (TakaraBio, Gothenburg, Sweden), and the real-time quantitative polymerase chain reaction (RT-qPCR) was prepared following the manufacturer's instructions. Reactions were carried out in a Pikoreal 96 realtime PCR system (Thermo Fisher Scientific) to measure the mRNA levels of the genes. The primers used are given in the table below. Glyceraldehyde 3-phosphate dehydrogenase (GAPDH) was considered an internal control for mRNA, and the data was analyzed using the $2^{-\Delta \Delta C t}$ method. All the measurements were repeated in triplicate (Table 1).

Table 1. Primer sequences

\begin{tabular}{|l|l|}
\hline \multicolumn{1}{|c|}{ Primers } & Sequence \\
\hline Caspase-3 Forward & ACTGGACTGTGGCATTGAGA \\
\hline Caspase-3 Reverse & GTTTCAGCATGGCACAAAGC \\
\hline IL-8 Forward & GTGGTGGCAGATGTGCTTAG \\
\hline IL-8 Reverse & TTCAGAGCCACAAACAAGGC \\
\hline IL-1 $\beta$ Forward & CTCTCTCCTTTCAGGGCCAA \\
\hline IL-1 $\beta$ Reverse & GCGGTTGCTCATCAGAATGT \\
\hline GAPDH Forward & ACCCAGAAGACTGTGGATGG \\
\hline GAPDH Reverse & TCAGCTCAGGGATGACCTTG \\
\hline
\end{tabular}

\section{Keloid transplantation and treatment with Ph1-PDT}

Male Bagg albino laboratory-bred (BALB) nude mice (18 \pm 2 g; 4-6 weeks old; 12 in each group) were kept in a pathogen-free environment. All the animals were provided by Tianjin Saierbio Co. (Tianjin, China). Prior to transplantation, all mice were acclimatized for 2 weeks (20 $\pm 2 \mathrm{~g})$. All the animal assays were performed strictly in accordance with the regulations of the 983rd PLA Hospital. 
Eye scissors were used to make an incision $(8 \mathrm{~mm}$ in length) for transplant of the keloid tissues (ATCC). The incision was stitched immediately after the keloid graft filled the gap between the subcutaneous tissues and the skin. Ph1 was injected into the nude rats via tail veins 15 days after the keloid implantation. A semiconductor laser with a $532 \mathrm{~nm}$ wavelength (model number FD5325-A; Wuhan Lingyun Photoelectric Technology, Wuhan, China) was used on the keloid graft for $10 \mathrm{~min}$. This laser equipment was selected as its wavelength is quite close to the oxyhemoglobin absorption peak (542 nm). Ph1-PDT group (100 $\mathrm{mW} \mathrm{cm} \mathrm{cm}^{-2}$ laser $+8 \mu \mathrm{g}$ Ph1 per mouse) underwent irradiation again on day 7 and 14 . The normal saline (NS) and TA $(0.1 \mathrm{mg} / \mathrm{mouse})$ group was not exposed to laser. The nude mice were treated with Ph1-PDT $\left(100 \mathrm{~mW} \mathrm{~cm}^{-2}\right.$ laser $+8 \mu \mathrm{g}$ Ph1/mouse), NS and TA $(0.1 \mathrm{mg} / \mathrm{mouse}$ without light) on day 7 and 14, respectively. The volume of NS and TA injected into the nude mice was $0.1 \mathrm{~mL}$. The control group received no injection and no light.

\section{Western blot analysis}

Mice were anesthetized using a 10\% chloral hydrate solution, the keloid blocks were removed surgically and stored at $-80^{\circ} \mathrm{C}$ for 21 days. The frozen keloid tissues were defrosted, homogenized in lysis buffer and centrifuged at $4{ }^{\circ} \mathrm{C}$ for $20 \mathrm{~min}$ at $12,000 \mathrm{rpm}$ to gather supernatants. Sodium lauryl sulfate loading buffer was used to lyse the cells for immunoblot and samples were stored at $-80^{\circ} \mathrm{C}$ until use. The supernatants were exposed to electrophoresis. After the proteins were separated and transferred to polyvinylidene fluoride (PVDF) membranes, the membranes were blocked for $2 \mathrm{~h}$ with bovine serum albumin (BSA, 1\% w/v). This was followed by incubation with primary antibodies against CD31 (ab222783; 1 : 2000; Abcam), CD34 (ab81289; 1 : 10000; Abcam), tumor growth factor $\beta 1$ (TGF- $\beta 1$; ab215715; 1 : 1000; Abcam), collagen 1 (ab34710; $1: 2000$; Abcam), and GAPDH (ab8245; $1: 2000 ;$ Abcam) at $4^{\circ} \mathrm{C}$ for $12 \mathrm{~h}$. After washing with PBS 3 times for $5 \mathrm{~min}$, the membranes were incubated with Goat Anti-Rabbit lgG H\&L (horseradish peroxidase (HRP); ab205718; 1 : 2000; Abcam) secondary antibody for $2 \mathrm{~h}$ at $4^{\circ} \mathrm{C}$. A Chemi Doc XRS system (Bio-Rad) was used to visualize the proteins.

\section{Statistical analysis}

SPSS v. 19.0 (IBM Corp., Armonk, USA) and GraphPad Prism v. 7.0 (GraphPad Software, San Diego, USA) were used for the analyses; all data are presented as mean \pm standard deviation (SD). Differences between the groups were determined using Student's t-test (for 2 groups) and oneway analysis of variance (ANOVA) for multiple groups. Bonferroni's correction was used for the post hoc comparisons. An alpha value of $\mathrm{p}<0.05$ was regarded as statistically significant.

\section{Results}

\section{Ph1-PDT suppresses keloid fibroblast viability, invasion and migration}

To investigate the impact of Ph1-PDT on keloid in vitro, we examined the effects of different concentrations of Ph1PDT on the cell viability of keloid fibroblasts using a CCK-8 assay. The results indicated that cell viability was significantly reduced in the PDT groups with Ph1 treatments ( $\mathrm{p}<0.05-0.001)$ compared to the control DMEM group without Ph1-PDT treatment (Fig. 1A). The $1 \mu \mathrm{M}$ and $3 \mu \mathrm{M}$ Ph1 groups were used for further experiments. In addition, we explored the impact of Ph1-PDT on the invasion and migration of keloid fibroblasts using scratch and invasion assays. The results revealed that the cells in the $1 \mu \mathrm{M}$ Ph1, $3 \mu \mathrm{M}$ Ph1, and TA groups showed a significantly weaker wound healing ability compared to the control group ( $p<0.05-0.01$; Fig. 1B). Moreover, invasion assays revealed that the $3 \mu \mathrm{M}$ Ph1 and TA groups showed a significantly weaker invasion capability compared to the control group ( $\mathrm{p}<0.05-0.01$ ), while there was no significant difference between the $1 \mu \mathrm{M}$ Ph1 group and the control (not significant (ns); Fig. 1C). These data indicates that Ph1-PDT markedly reduces the migration and invasion of keloid fibroblasts.

\section{Effect of Ph1-PDT on keloid fibroblast apoptosis}

The impact of Ph1-PDT on keloid fibroblast apoptosis was determined using flow cytometry. Our results showed that the rate of apoptosis was enhanced in the $1 \mu \mathrm{M}$ group ( $\mathrm{p}<0.05$, compared to the control), which was less significant than that observed for the $3 \mu \mathrm{M}$ Ph1 and TA groups ( $\mathrm{p}<0.01$, compared to the control, Fig. 2A,B). In addition, the mRNA expression of caspase-3 in keloid fibroblasts was determined using RT-qPCR, and was found to be significantly higher in the cells treated with $1 \mu \mathrm{M}$ Ph1 ( $\mathrm{p}<0.05), 3 \mu \mathrm{M}$ Ph1 $(\mathrm{p}<0.01)$ or TA $(\mathrm{p}<0.01)$, compared to the control group (Fig. 2C) These data demonstrate that Ph1-PDT treatment promotes apoptosis in keloid fibroblasts.

\section{Effect of Ph1-PDT on growth and vessel density in keloid grafts}

Keloid tissues were transplanted into nude mice and the impact of Ph1-PDT on the growth of keloid in vivo was examined. Following the transplant, the mice were treated with Ph1-PDT, NS or TA, or remained untreated, as outlined above. It was found that Ph1-PDT treatment significantly decreased the volume of the graft $(\mathrm{p}<0.01$; Fig. 3A). In addition, to evaluate the vessel density in keloid grafts, the protein expression of CD31 and CD34 were determined using western blot analysis. Results showed 
A

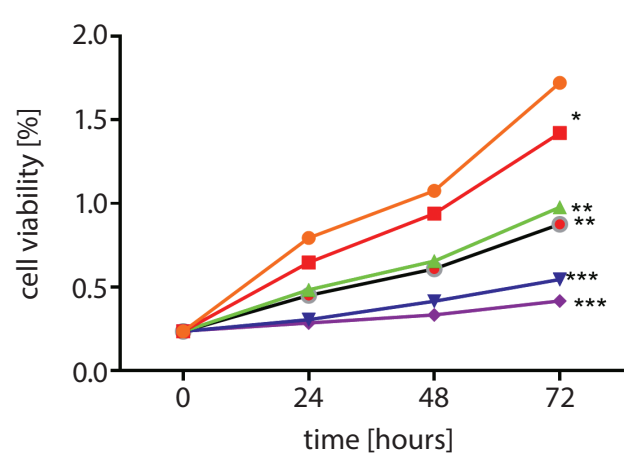

- control

- $1 \mu \mathrm{MPh} 1$

$-3 \mu \mathrm{MPh} 1$

$\rightarrow \quad 10 \mu \mathrm{MPh} 1$

$\multimap 30 \mu \mathrm{MPh} 1$

-e- TA [1 mg/mL]
Fig. 1. Ph1-PDT suppressed keloid fibroblast viability, invasion and migration. A. CCK-8 assay was used to measure the viability of keloid fibroblast after different treatments; $B$. The number of migrated cells in keloid fibroblasts was determined using scratch migration assay; $C$. The wound healing rate of keloid fibroblast was detected after $24 \mathrm{~h}$ and $48 \mathrm{~h}$. Compared the control group, which was treated with DMEM

*** $p<0.001$; ** $p<0.01$; ${ }^{*} p<0.05 ;$ ns - not significant.

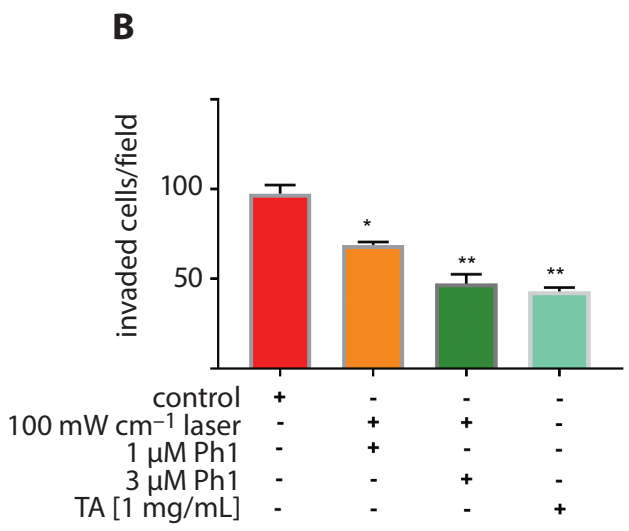

that Ph1-PDT significantly reduced the protein expression of CD31 and CD34, implying that the vessel density was decreased by Ph1-PDT treatment in vivo ( $p<0.05-0.01$; Fig. 3B,C). Collectively, these data demonstrate that Ph1PDT suppresses the growth and vessel density of keloid grafts in vivo.

\section{Ph1-PDT inhibits the expression of TGF- $\beta 1$ and collagen 1 in keloid fibroblasts and keloid grafts}

Next, we determined the protein expression of TGF- $\beta 1$ and collagen 1 in keloid fibroblasts and keloid grafts using western blot analysis. The results show that Ph1PDT treatment significantly reduces the protein expression of TGF- $\beta 1$ and collagen 1 both in vitro and in vivo ( $<<0.05-0.01$; Fig. 4A,B).

\section{Effect of Ph1-PDT on inflammatory mediators in keloid grafts}

Using ELISA assays and RT-qPCR, the 2 inflammatory modulators (IL-8 and IL-1 $\beta$ ) were detected in the keloid grafts. The results revealed that Ph1-PDT treatment significantly reduces the protein concentration and the mRNA expression of IL-1 $\beta$ and IL-8 compared to the control (TA) group ( $<$ <.01; Fig. 5A,B).

\section{Discussion}

Keloid is characterized by the hyperproliferation of fibroblasts and excess collagen deposition due to an abnormal wound healing process after skin injury. Keloid acts like a tumor by invading the adjacent skin and spreading beyond the margins of the wound boundary. ${ }^{21}$ Traditional therapies for keloids exhibit some drawbacks, including a high risk of palindromes, side effects and low efficacy. ${ }^{22}$ Therefore, a more effective and safer technique for the treatment of keloid is urgently needed. The PDT, together with the photosensitizer 5-ALA, has previously been reported to induce apoptosis in fibroblasts and reduce the growth of a keloid graft. ${ }^{23}$ It has also been observed previously that HMMEPDT treatment enhances the apoptosis rate of keloid fibroblasts. ${ }^{23}$ In the current study, PDT and the photosensitizing agent Ph1 were investigated under different conditions and light powers both in vitro and in vivo.

Microvessel density is considered as a factor for angiogenesis and keloid maturation. ${ }^{24}$ CD31 and CD34 are vascular endothelial markers and can be used as a reference for vessel density in differentiated endothelial cells, ${ }^{25}$ as CD31 and CD34 promote angiogenesis and tumor growth. ${ }^{26} \mathrm{~A}$ recent study demonstrated that the expression of CD31 and CD34 were inhibited by 5-ALA-mediated PDT in oral leukoplakia. ${ }^{27}$ In the current study, it was observed that CD31 and CD34 protein expression were significantly decreased 
A
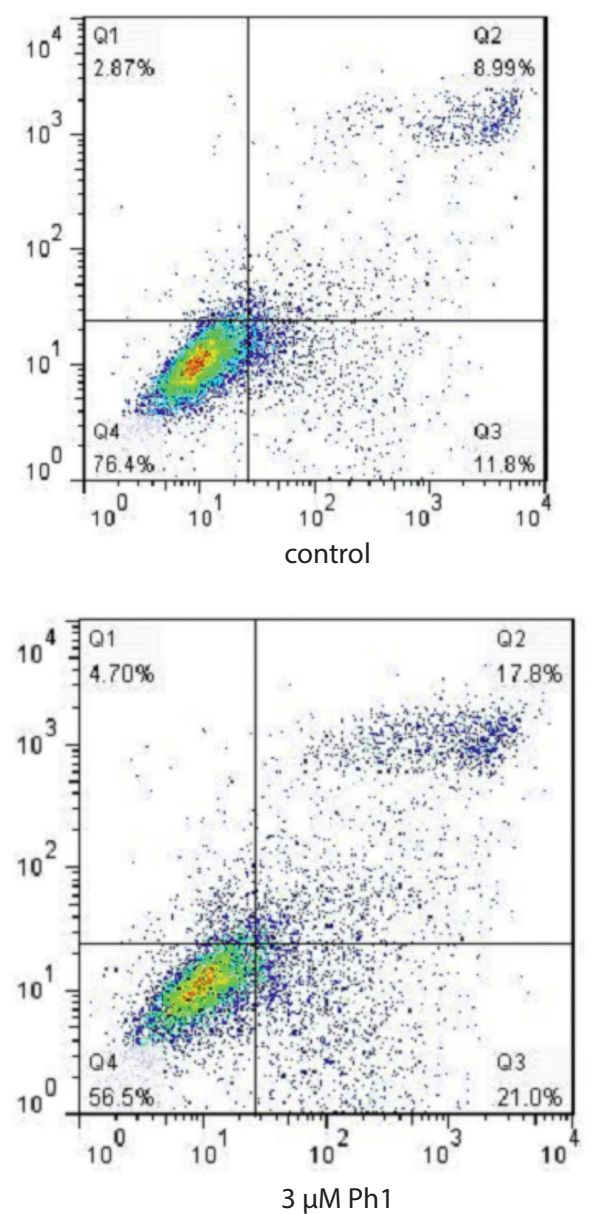

B

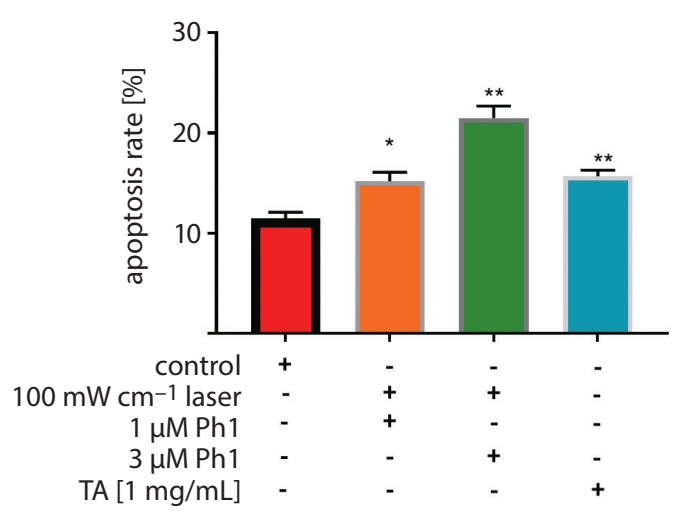

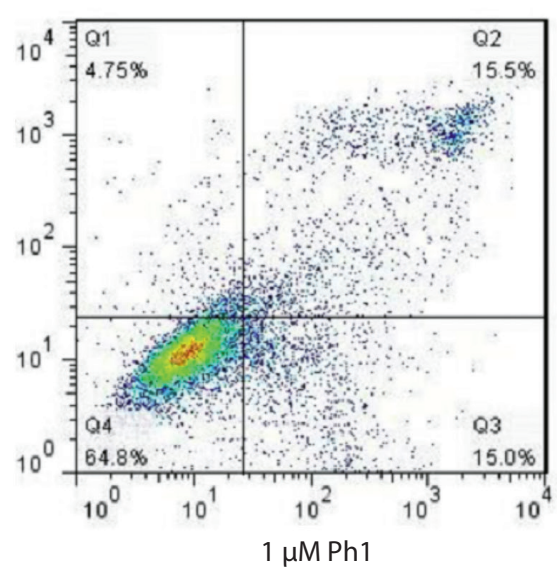
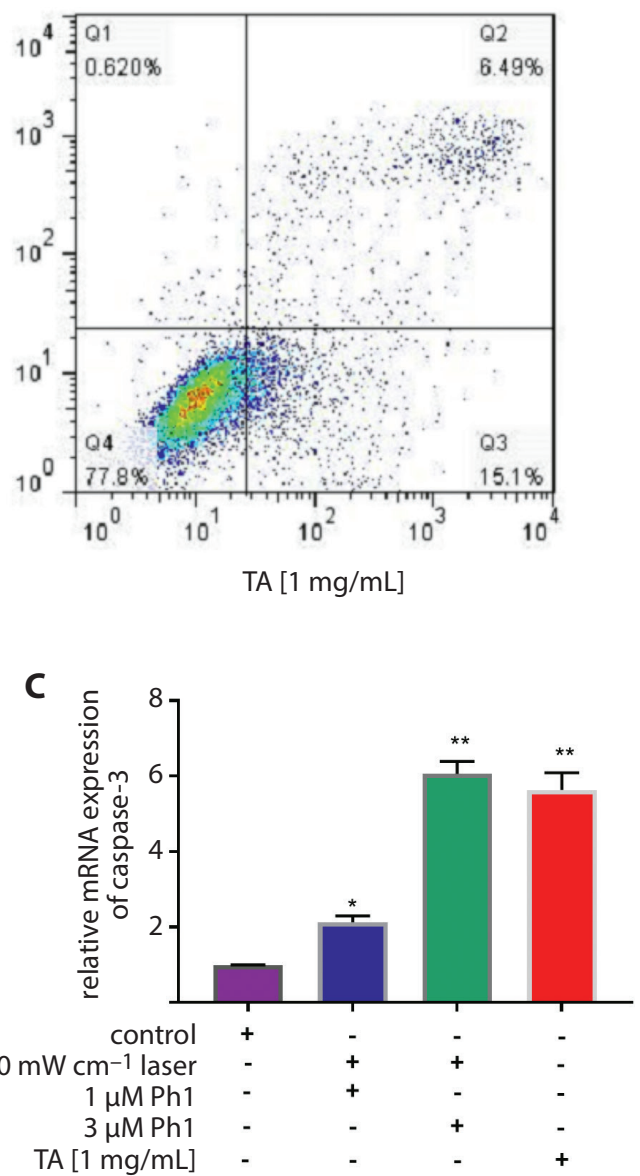

and the volume of the keloid graft was reduced by Ph1-PDT treatment.

Previous work has shown that MPPa-PDT significantly reduces the invasion and migration of MCF-7 cells. ${ }^{28} \mathrm{In}$ addition, 5-ALA-PDT markedly suppresses cell migration and invasion in A431 cells by enhancing apoptosis in cutaneous squamous cell carcinoma. ${ }^{29}$ It has also been reported that Ph1-PDT activates the apoptotic-related proteins caspase-3 and caspase-8, inducing cell apoptosis. ${ }^{30}$ Interestingly, our findings showed that Ph1-PDT reduces keloid fibroblast migration and invasion, and promotes apoptosis. In combination with the abovementioned results, our findings
Fig. 2. Effect of Ph1-PDT on keloid fibroblast apoptosis. A and B. The rate of apoptosis of keloid fibroblasts was measured using flow cytometry after different treatments; C. RT-qPCR was used to determine the mRNA expression of caspase-3 in keloid fibroblasts after different treatments. Compared to the control group, which was treated with DMEM

${ }^{* * *} p<0.001 ; * * 0.01$ ${ }^{*} p<0.05 ;$ ns - not significant. suggest that Ph1-PDT might be a novel and efficient technique for keloid treatment.

The TGF- $\beta 1$ is an important regulator in the progression of keloid due to its various biological functions in wound healing. ${ }^{31}$ An earlier study elucidated the mechanism of 5-ALA-mediated PDT, and demonstrated that TGF- 31 -mediated signaling and p53-related apoptosis might be an important factor for the treatment of hypertrophic scars. ${ }^{32}$ The excessive accumulation of collagens (collagen 1 and collagen 3 ) and hypernomic development of fibroblasts are considered as the critical characteristics in the formation of keloid. ${ }^{33}$ Our results showed 
A

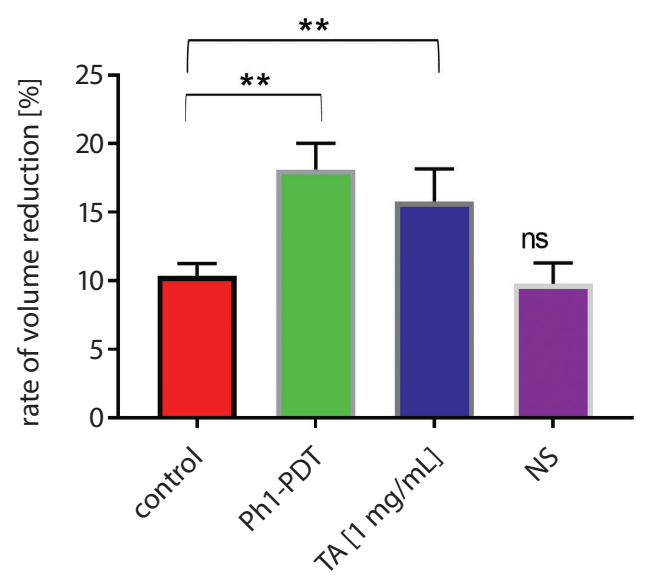

B

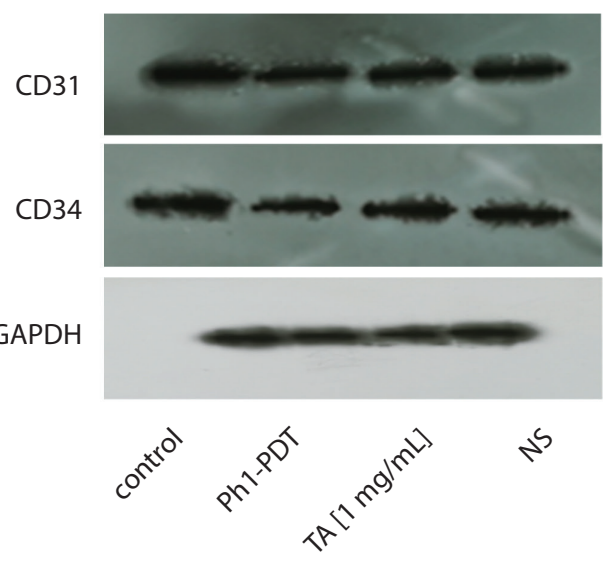

Fig. 3. Effect of Ph1-PDT on growth and vessel density in keloid grafts. A. The rate of keloid volume reduction was calculated based on that data collected by calipers in keloid graft. B and C. Western blot analysis was used to determine the protein expressions of CD31 and CD34 in keloid graft. Compared to control group in vivo, which was the group without treatment

*** $p<0.001$; ** $p<0.01$; $p<0.05$; ns - not significant.

C

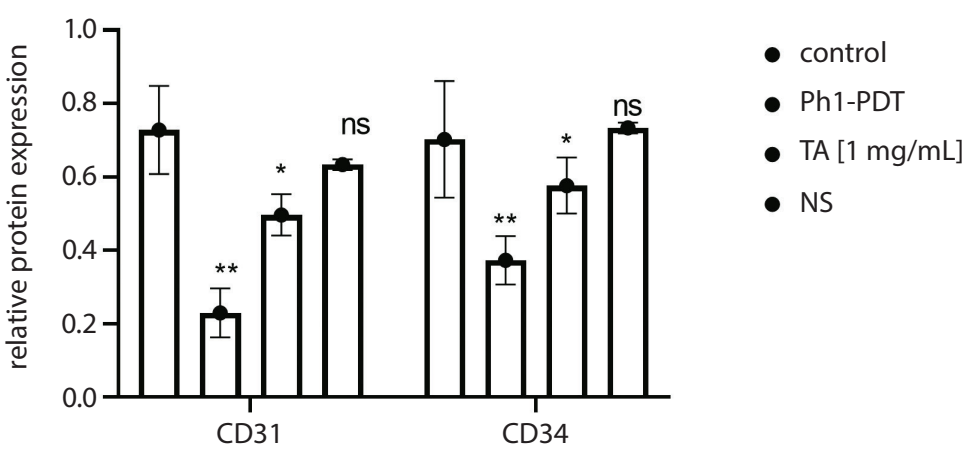

A
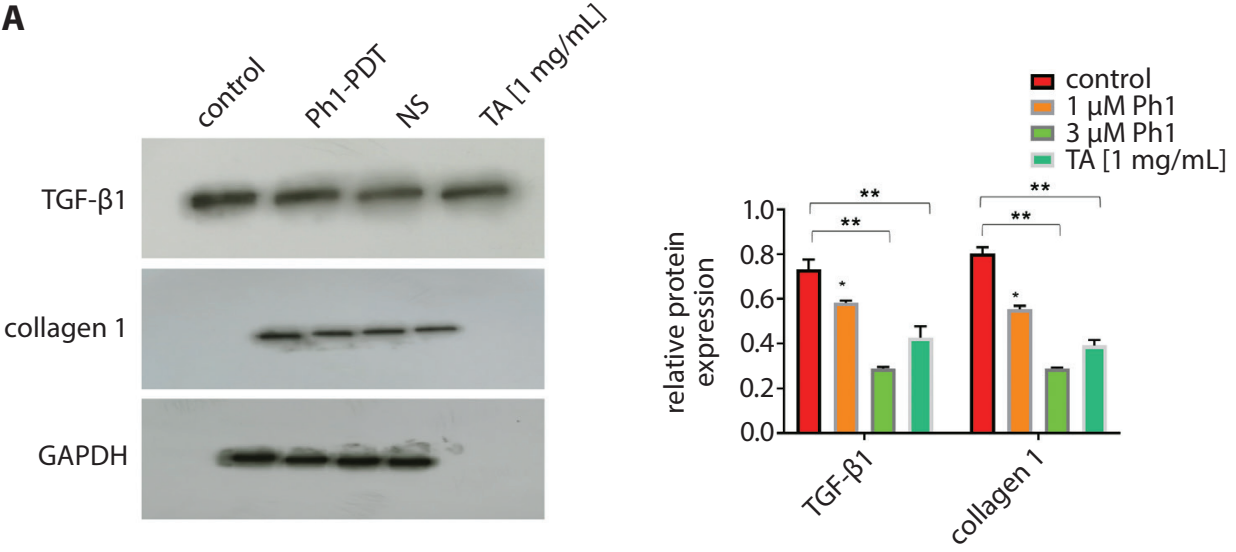

B
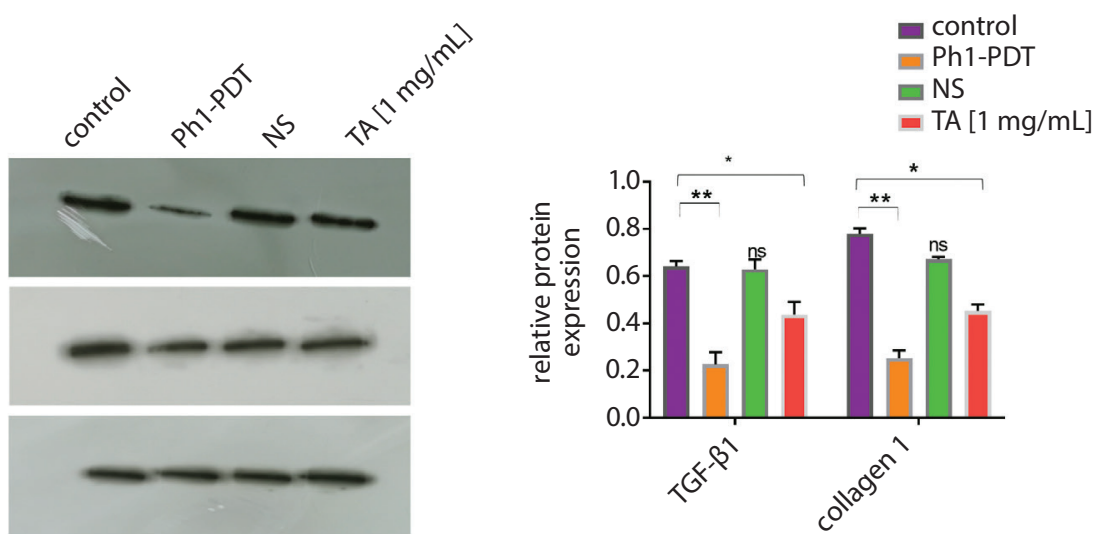

Fig. 4. Ph1-PDT inhibited

the expression of TGF- $\beta$ and collagen 1 in keloid fibroblasts

and keloid graft. A and

B. Western blot analysis was

used to determine the protein expressions of TGF- $\beta$ and

collagen 1 in keloid fibroblasts and keloid graft after different treatments. Compared to contro group in vivo, which was the group without treatment, and to control group in vitro, which was treated with DMEM

${ }^{* * *} p<0.001 ;{ }^{* *} p<0.01$ ${ }^{*} p<0.05 ;$ ns - not significant.

TGF- $\beta 1$

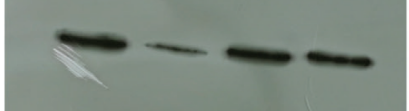

collagen 1

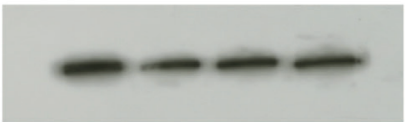

GAPDH

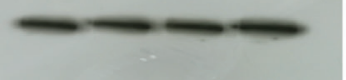


A

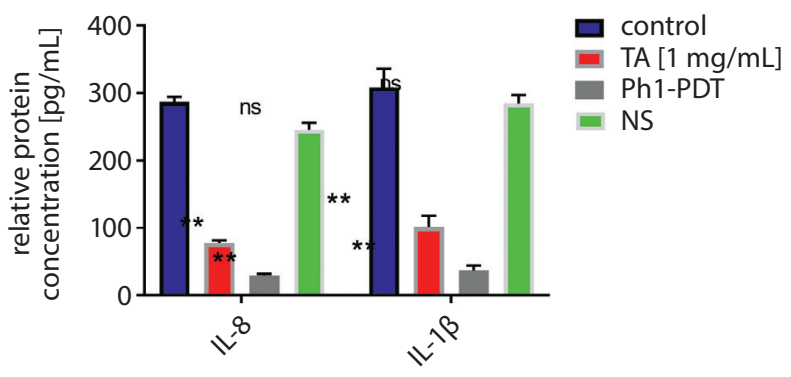

B

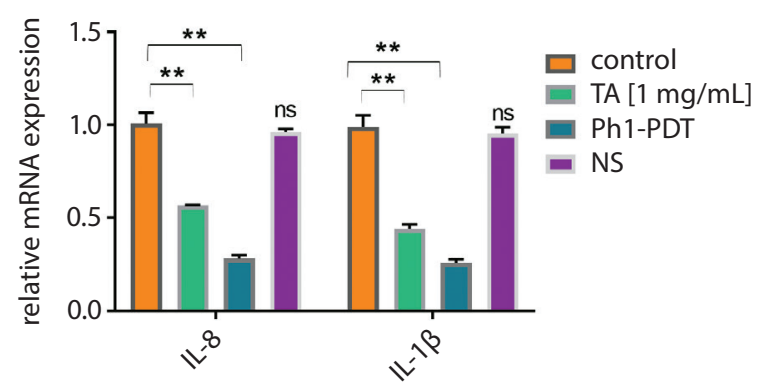

Fig. 5. Effect of Ph1-PDT on inflammatory mediators in keloid grafts: $A$ and B. ELISA assay and RT-qPCR were used to determine the protein concentration and mRNA expression of IL-8 and IL-1 $\beta$ in keloid fibroblasts. Compared to control group in vivo, which was the group without treatment, and to control group in vitro, which was treated with DMEM

*** $p<0.001$; ${ }^{* *} p<0.01$; $p<0.05$; ns - not significant.

that Ph1-PDT downregulated the expression of TGF- $\beta 1$ and collagen 1, indicating that Ph1-PDT dysregulated the TGF- $\beta 1 /$ collagen 1 pathway involved the pathogenesis of keloid.

The basic healing process after PDT treatment is complex and dynamic, including biochemical, molecular and cellular actions that terminate in the re-development of impaired tissues. ${ }^{23}$ Previous work has shown that the levels of pro-inflammatory cytokines (IL-6, IL-1 $\beta$ and IL-8) are markedly reduced after PDT in chronic periodontitis. ${ }^{34}$ An earlier study has also observed the inhibition of inflammatory modulators (IL-6, IL-8 and tumor necrosis factor $\alpha$ (TNF- $\alpha)$ ) after PDT in humans. ${ }^{35}$ Furthermore, a study in an animal model of skin scars and striae distensae showed that pro-inflammatory cytokines were dramatically inhibited after PDT therapy. ${ }^{36}$ Consistent with these previous studies, our findings demonstrate that Ph1-PDT significantly inhibits the protein concentration and the mRNA expression of the inflammatory cytokines IL- $1 \beta$ and IL- 8 in keloid fibroblasts. Regardless of this, the suppression impact of PDT on keloid fibroblasts in lieu of inflammation stimulation was favorable for keloid treatment.

\section{Limitations}

Limitations of this study lie in the lack of further investigations into classical signaling pathways involved in this study.

\section{Conclusions}

The current study shows that Ph1-PDT inhibits keloid growth both in vitro and in vivo, suggesting that Ph1-PDT may potentially serve as a therapeutic strategy for keloid.

\section{ORCID iDs}

Wei Zheng (D) https://orcid.org/0000-0001-6848-3537 Haiyan Wu (D) https://orcid.org/0000-0002-0589-9663 Ying Li (D) https://orcid.org/0000-0002-8247-7034

Helin Li (D) https://orcid.org/0000-0002-4528-644X

Zhaojun Liu (D) https://orcid.org/0000-0003-0419-7296

Yongzhi Nie (D) https://orcid.org/0000-0003-0184-3846 Lingling Shi (1) https://orcid.org/0000-0002-5506-746X

Hongyu Wang (D) https://orcid.org/0000-0002-6657-8775

\section{References}

1. Kim SH, Jung $\mathrm{SH}$, Chung $\mathrm{H}$, et al. Annexin $\mathrm{A} 2$ participates in human skin keloid formation by inhibiting fibroblast proliferation. Arch Dermatol Res. 2014;306(4):347-357. doi:10.1007/s00403-014-1438-x

2. Smith OJ, McGrouther DA. The natural history and spontaneous resolution of keloid scars. J Plast Reconst Aesthet Surg. 2014;67(1):87-92. doi:10.1016/j.bjps.2013.10.014

3. Celli JP, Spring BQ, Rizvi I, et al. Imaging and photodynamic therapy: Mechanisms, monitoring, and optimization. Chem Rev. 2010;110(5): 2795-2838. doi:10.1021/cr900300p

4. Kerwin LY, El Tal AK, Stiff MA, Fakhouri TM. Scar prevention and remodeling: A review of the medical, surgical, topical and light treatment approaches. Int J Dermatol. 2014;53(8):922-936. doi:10.1111/ ijd.12436

5. McKeown SR, Hatfield P, Prestwich RJ, Shaffer RE, Taylor RE. Radiotherapy for benign disease: Assessing the risk of radiation-induced cancer following exposure to intermediate dose radiation. Br J Radiol. 2015;88(1056):20150405. doi:10.1259/bjr.20150405

6. Christensen E, Warloe T, Kroon S, et al. Guidelines for practical use of MAL-PDT in non-melanoma skin cancer. J Eur Acad Dermatol Venereol. 2010;24(5):505-512. doi:10.1111/j.1468-3083.2009.03430.x

7. Gu T, Cheng L, Gong F, et al. Upconversion composite nanoparticles for tumor hypoxia modulation and enhanced near-infrared-triggered photodynamic therapy. ACS Appl Mater Interfaces. 2018;10(18): 15494-15503. doi:10.1021/acsami.8b03238

8. Maisch T. Anti-microbial photodynamic therapy: Useful in the future? Lasers Med Sci. 2007;22(2):83-91. doi:10.1007/s10103-006-0409-7

9. Alves $E$, Costa L, Carvalho CM, et al. Charge effect on the photoinactivation of Gram-negative and Gram-positive bacteria by cationic meso-substituted porphyrins. BMC Microbiol. 2009;9:70. doi:10.1186/ 1471-2180-9-70

10. Dougherty TJ, Gomer CJ, Henderson BW, et al. Photodynamic therapy. J Nat/ Cancer Inst. 1998;90(12):889-905. doi:10.1093/jnci/90.12.889

11. Kessel D, Oleinick NL. Cell death pathways associated with photodynamic therapy: An update. Photochem Photobiol. 2018;94(2):213-218. doi:10.1111/php.12857

12. Salmerón ML, Quintana-Aguiar J, De La Rosa JV, et al. Phenalenonephotodynamic therapy induces apoptosis on human tumor cells mediated by caspase-8 and p38-MAPK activation. Mol Carcinog. 2018; 57(11):1525-1539. doi:10.1002/mc.22875

13. Foote CS. Definition of type I and type II photosensitized oxidation. Photochem Photobiol. 1991;54(5):659. doi:10.1111/j.1751-1097.1991. tb02071.x

14. Wang X, Li J, Li L, Li X. Photodynamic therapy-induced apoptosis of keloid fibroblasts is mediated by radical oxygen species in vitro. Clin Lab. 2015;61(9):1257-1266. doi:10.7754/clin.lab.2015.150222

15. Plaetzer K, Kiesslich T, Oberdanner CB, Krammer B. Apoptosis following photodynamic tumor therapy: Induction, mechanisms and detection. Curr Pharm Des. 2005;11(9):1151-1165. doi:10.2174/138161 2053507648

16. Luna MC, Ferrario A, Wong S, Fisher AM, Gomer CJ. Photodynamic therapy-mediated oxidative stress as a molecular switch for the temporal expression of genes ligated to the human heat shock promoter. Cancer Res. 2000;60(6):1637-1644. PMID:10749134 
17. Zheng Z, Zhu L, Zhang X, et al. RUNX3 expression is associated with sensitivity to pheophorbide a-based photodynamic therapy in keloids. Lasers Med Sci. 2015;30(1):67-75. doi:10.1007/s10103-014-1614-4

18. Song R, Feng Y, Wang D, Xu Z, Li Z, Shao X. Phytoalexin phenalenone derivatives inactivate mosquito larvae and root-knot nematode as type-II photosensitizer. Sci Rep. 2017;7:42058. doi:10.1038/ srep42058

19. Späth A, Leibl C, Cieplik F, et al. Improving photodynamic inactivation of bacteria in dentistry: Highly effective and fast killing of oral key pathogens with novel tooth-colored type-II photosensitizers. J Med Chem. 2014;57(12):5157-5168. doi:10.1021/jm4019492

20. Chen AD, Chen RF, Li YT, et al. Triamcinolone acetonide suppresses keloid formation through enhancing apoptosis in a nude mouse model. Ann Plast Surg. 2019;83(4S Suppl 1):S50-S54. doi:10.1097/sap. 0000000000002090

21. Jagadeesan J, Bayat A. Transforming growth factor beta (TGFbeta) and keloid disease. Int J Surg. 2007;5(4):278-285. doi:10.1016/j.ijsu. 2006.04.007

22. Liu T, Ma X, Ouyang T, et al. Efficacy of 5-aminolevulinic acid-based photodynamic therapy against keloid compromised by downregulation of SIRT1-SIRT3-SOD2-mROS dependent autophagy pathway. Redox Biol. 2019;20:195-203. doi:10.1016/j.redox.2018.10.011

23. Cui X, Zhu J, Wu X, et al. Hematoporphyrin monomethyl ether-mediated photodynamic therapy inhibits the growth of keloid graft by promoting fibroblast apoptosis and reducing vessel formation. Photochem Photobiol Sci. 2020;19(1):114-125. doi:10.1039/c9pp00311h

24. Folkman J. Angiogenesis and breast cancer. J Clin Oncol. 1994;12(3): 441-443. doi:10.1200/jco.1994.12.3.441

25. Poblet E, Gonzalez-Palacios F, Jimenez FJ. Different immunoreactivity of endothelial markers in well and poorly differentiated areas of angiosarcomas. Virchows Arch. 1996;428(4-5):217-221. doi:10.1007/ bf00196693

26. Teo NB, Shoker BS, Jarvis C, Martin L, Sloane JP, Holcombe C. Vascular density and phenotype around ductal carcinoma in situ (DCIS) of the breast. BrJCancer. 2002;86(6):905-911. doi:10.1038/sj.bjc.6600053

27. Rosin FC, Barcessat AR, Borges GG, Ferreira LG, Corrêa L. Vascular alterations after photodynamic therapy mediated by 5 -aminolevulinic acid in oral leukoplakia. Lasers Med Sci. 2017;32(2):379-387. doi:10.1007/s10103-016-2127-0
28. Huang $\mathrm{L}$, Lin $\mathrm{H}$, Chen $\mathrm{Q}$, Yu L, Bai D. MPPa-PDT suppresses breast tumor migration/invasion by inhibiting Akt-NF-KB-dependent MMP-9 expression via ROS. BMC Cancer. 2019;19(1):1159. doi:10.1186/s12885019-6374-X

29. Chi YF, Qin JJ, Li Z, Ge Q, Zeng WH. Enhanced anti-tumor efficacy of 5-aminolevulinic acid-gold nanoparticles-mediated photodynamic therapy in cutaneous squamous cell carcinoma cells. Braz JMed Biol Res. 2020;53(5):e8457. doi:10.1590/1414-431×20208457

30. Zhuang S, Demirs JT, Kochevar IE. p38 mitogen-activated protein kinase mediates bid cleavage, mitochondrial dysfunction, and caspase- 3 activation during apoptosis induced by singlet oxygen but not by hydrogen peroxide. J Biol Chem. 2000;275(34):25939-25948. doi:10.1074/jbc.M001185200

31. Lee TY, Chin GS, Kim WJ, Chau D, Gittes GK, Longaker MT. Expression of transforming growth factor beta 1, 2, and 3 proteins in keloids. Ann Plast Surg. 1999;43(2):179-184. PMID:10454326

32. Chang M, Ma X, Ouyang $T$, et al. Potential molecular mechanisms involved in 5-aminolevulinic acid-based photodynamic therapy against human hypertrophic scars. Plast Reconstr Surg. 2015;136(4): 715-727. doi:10.1097/prs.0000000000001626

33. Lin L, Wang Y, Liu W, Huang Y. BAMBI inhibits skin fibrosis in keloid through suppressing TGF- $\beta 1$-induced hypernomic fibroblast cell proliferation and excessive accumulation of collagen I. Int J Clin Exp Med. 2015;8(8):13227-13234. PMID:26550247

34. Luchesi VH, Pimentel SP, Kolbe MF, et al. Photodynamic therapy in the treatment of class II furcation: A randomized controlled clinical trial. J Clin Periodontol. 2013;40(8):781-788. doi:10.1111/jcpe.12121

35. Nesi-Reis V, Lera-Nonose D, Oyama J, et al. Contribution of photodynamic therapy in wound healing: A systematic review. Photodiagnosis Photodyn Ther. 2018;21:294-305. doi:10.1016/j.pdpdt.2017.12.015

36. Mendoza-Garcia J, Sebastian A, Alonso-Rasgado T, Bayat A. Ex vivo evaluation of the effect of photodynamic therapy on skin scars and striae distensae. Photodermatol Photoimmunol Photomed. 2015;31(5): 239-251. doi:10.1111/phpp.12180 